\title{
The Epidemiology of COVID-19 Novel Corona Virus to Possibly Control the Disease and Other Factors Relating to Health Around the World
}

\author{
Ahsan Ali Siddiqui*, MD, MSPH, UK \\ Consultant Public Health, Quality Management \& Patient Safety Department, General Directorate of Health, Saudi Arabia
}

\begin{abstract}
Background and Objective: The main Aim and objective of this Article is to focus on Prevention and Control of COVID-19 novel corona virus. This article would also discuss the people with other illnesses are more Vulnerable to get COVID-19 Complications leading to severe conditions of Morbidity and later Mortality.
\end{abstract}

Methods: The Author of this Article has done Literature Review, Comparison and Critical analysis of more than 20 Published Articles and other reviews. Author has chosen the Comparative Literature review as methodology for this research article. The purpose is to show that Randomly chosen articles are in favor of immediate Preventions implication against Pandemic of COVID-19 Novel corona virus. SPSS 19 software is used to show Diagrammatic presentation for the results and analysis.

Results: Author of this articles has selected randomly 15 Articles from PUBMED and other sources for review and critical analysis about the Articles to focus on Prevention and Control of COVID-19 novel corona virus. First part of the table and SPSS1 Diagrammatic presentation shows that all 15 articles focus on implementation of policies and methods for Prevention and Control of COVID-19 novel corona virus. SPSS2 Diagrams shows the Percentages\% agreed of the Prevention and Control of COVID-19 novel corona virus where 10 Articles fully 100\% qualified but 5 articles are below $81 \%$ which is low in percentage.

Conclusion: Current Pandemic of COVID-19 has taught us that we in the twenty first century is not ready to provide health care to vulnerable community such as elders, children and sick people with chronic illness. Such vulnerable people with bad health and low socio-economic status are more prone to get effected by COVID-19 novel corona virus. More serious work needed to be done by Global health agencies and world organizations such as WHO, CDC, UN, UNESCO, UNHCR others. Governments and health departments has to make useful health policies to implement in deadlines with serious accountability to fight against any Epidemic or Pandemic.

KEYWORDS: COVID-19; Chloroquine; MERS; Morbidity; Remdesivir; SARS-CoV-2; Importing; Iran; Outbreaks; Spreading; Acute respiratory distress syndrome; Disability; Physical function; Physiotherapy drugs spillover; Pandemic; Oral and maxillofacial surgery; Personal protective equipment; Triage

Quick Response Code:

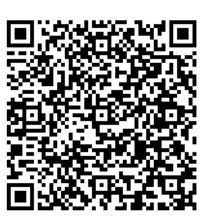

Address for correspondence: Ahsan Ali Siddiqui, MD, MSPH, UK, Consultant Public Health, Quality Management \& Patient Safety Department, General Directorate of Health, Riyadh Saudi Arabia

Received: May 21, 2020 Published: May 29, 2020

How to cite this article: Ahsan Ali Siddiqui, MD, MSPH, UK. The Epidemiology of COVID-19 Novel Corona Virus to Possibly Control the Disease and Other Factors Relating to Health Around the World. 2020 - 2(3) OAJBS.ID.000175. DOI: 10.38125/OAJBS.000175 


\section{INTRODUCTION}

You can reduce your chances of being infected World Health Organization [1] or spreading COVID-19 by taking some simple precautions such as Regularly and thoroughly clean your hands with an alcohol-based hand rub or wash them with soap and water. Maintain at least 1-meter or 3 feet distance between yourself and others. Why because when someone coughs, sneezes, or speaks they spray small liquid droplets from their nose or mouth which may contain virus. Avoid going to crowded places. Why because where people come together in crowds you are more likely to come into close contact with someone that has COIVD-19. Avoid touching eyes, nose and mouth. Why because hands touch many surfaces and can pick up viruses. Make sure you and the people around you follow good respiratory hygiene. Stay home and self-isolate even with minor symptoms such as cough, headache, mild fever, until you recover and have someone bring you supplies. If you have a fever, cough and difficulty breathing, seek medical attention, but call by telephone in advance if possible and follow the directions of your local health authority. Use alcohol-based hand sanitizer or World Health Organization [1] wash your hands with soap and water (Figure 1,2).
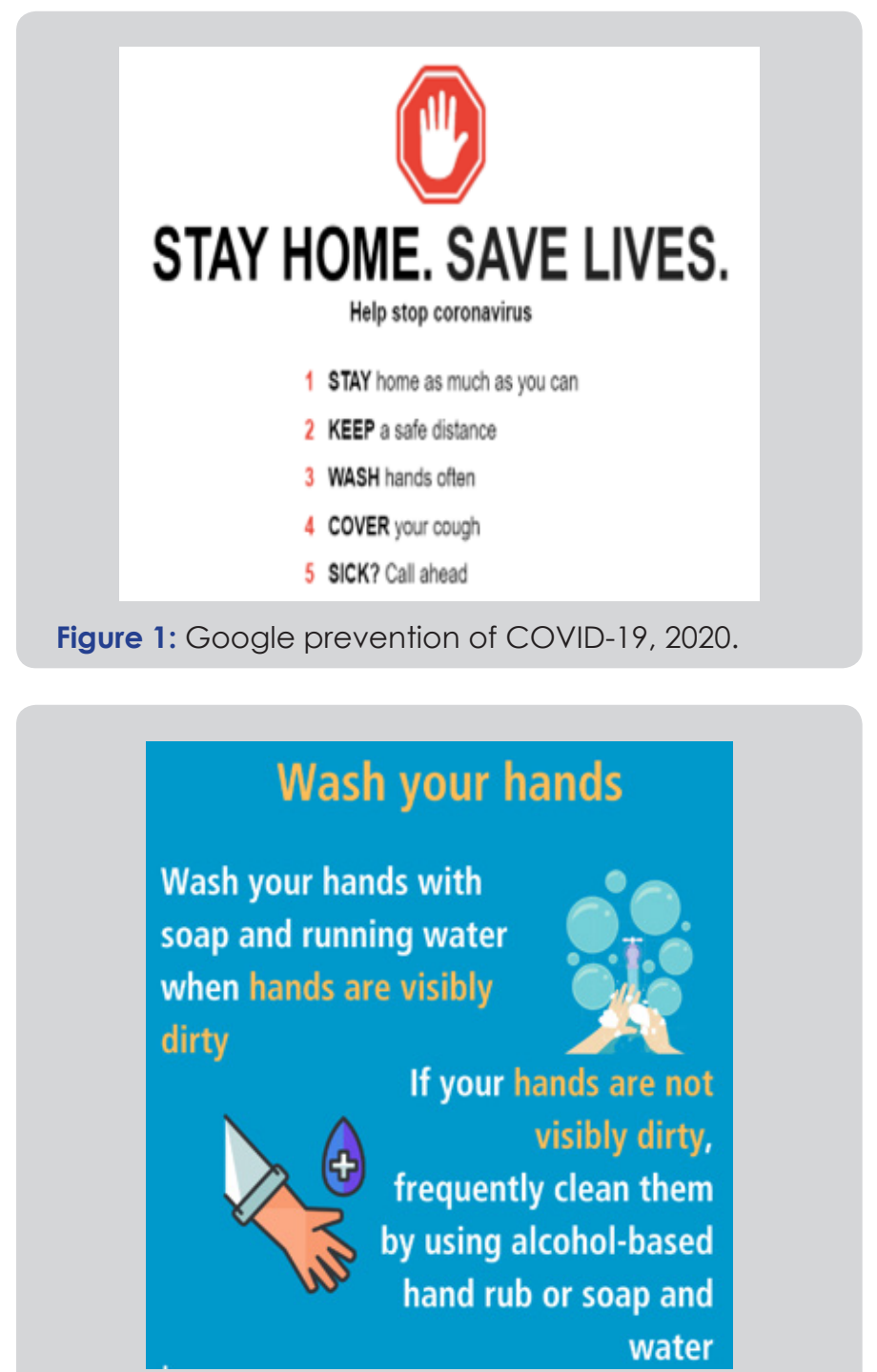

Figure 2: World Health Organization, 2020.

The transmission of COVID-19 is Fan [2] about to come under control within China however, an emerging challenge to the Chinese authorities is reverse transmission due to COVID-19 patients/ carriers. We analyzed the epidemiological characteristics of 311 Chinese citizens evacuated from Iran. All confirmed COVID-19 cases amongst the returnees were displayed by the spatial distribution pattern of the extent of COVID-19 infection. Characteristics that differed significantly amongst these returnees compared to the original infected cohorts in Gansu were mean age occupation and sex. Differences observed between infected patients and nonpatients amongst returnees were age, sex, race, occupation, the use of facemasks, and residential situation in Iran. The clinical features that were significantly related to infection were chill, shortness of breath, chest pain and nausea. Blocking the reverse transmission of COVID-19 is critical in preventing a secondary outbreak of Fan [2] COVID-19.

An epidemic of extreme respiratory Hasnain [3] deterrence pneumonia and shortness of breath the SARS-CoV-2 viral infection began in Wuhan Hubei Province China in December 2019 and rapidly spread across China and beyond with human to human transmission. On February 12, 2020 World Health Organization officially named the new coronavirus disease as coronavirus disease 19. Most COVID-19 patients were diagnosed with pneumonia and many were treated using Chinese medicines and other secondary therapies. Preliminary reports suggest that certain drugs such as chloroquine and antiviral nucleotide analogues such as remdesivir which inhibit viral replication can target the new coronavirus although their usefulness in the clinic is still under debate. This manuscript reviews the epidemiology etiology mortality COVID-19 clinical symptoms and potential therapeutic drugs, while highlighting the seriousness and Hasnain [3] damage-induced by SARS-CoV-2

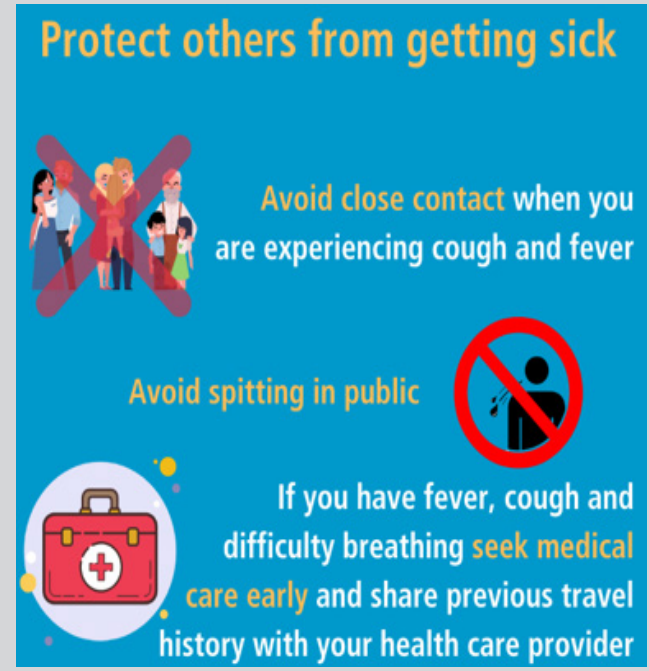

Figure 3: World Health Organization, 2020.

Since late November 2019 COVID-19 Sevim [4] has become a global health pandemic and threat. Although most people have no or mild symptoms COVID-19 spreads aggressively and can lead to ARDS rapidly in a proportion of individuals. The evidence supports that gas exchange and countering the negative effects of bed rest and immobility are priorities in severely affected patients admitted to the intensive care unit (ICU). However, in recent years research has focused on poor long-term functional outcomes in patients with ARDS often associated with ICU-acquired weakness deconditioning and myopathies and neuropathies. In addition to physical therapists providing respiratory support in the ICU the 
literature unequivocally supports the view that early intervention for ICU management of patients with ARDS. Secondary to COVID-19 needs to focus on reducing contributors to impaired long term function with direct attention paid to preventing or managing ICU acquired weakness deconditioning Sevim [4] and myopathies and neuropathies in conjunction with respiratory care (Figure 3,4).

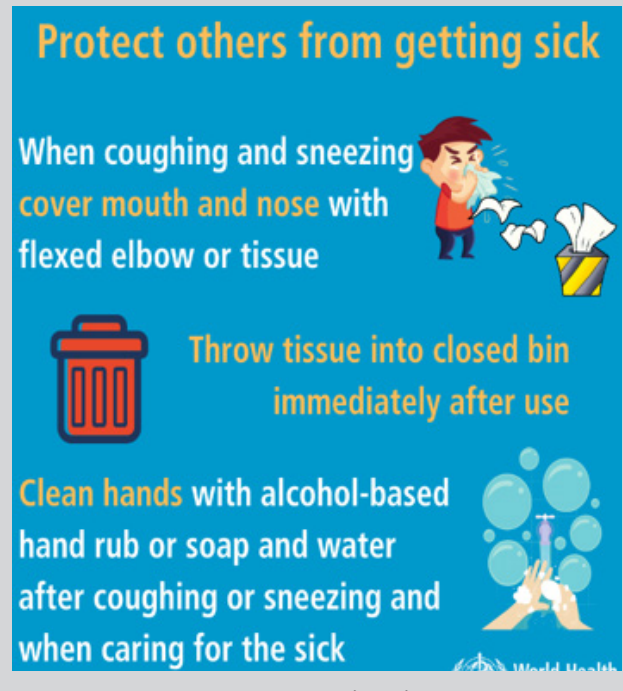

Figure 4: World Health Organization, 2020.

The outbreak of emerging Yuefei [5] severe acute respiratory syndrome coronavirus 2 (SARS-CoV-2) disease COVID-19 in China has been brought to global attention and declared a pandemic by the World Health Organization. Scientific advancements since the pandemic of severe acute respiratory syndrome SARS in 2002-2003 and Middle East respiratory syndrome MERS in 2012 have accelerated our understanding of the epidemiology and pathogenesis of SARS-CoV-2 and the development of therapeutics to treat viral infection. As no specific therapeutics and vaccines are available for disease control the epidemic of COVID-19 is posing a great threat for global public health. To provide a comprehensive summary to public health authorities and potential readers worldwide we detail the present understanding of COVID-19 and Yuefei [5] introduce the current state of development of measures in this review.

\section{METHODS}

The Author of this Article has done Literature Review, Comparison and Critical analysis of more than 20 Published Articles and reviews. Author has chosen the Comparative Literature review as methodology for this research article. The purpose is to show that Randomly chosen articles are in favor of immediate Preventions implication against Pandemic of COVID-19 Novel corona virus. A literature review Royal Literacy Fund [6] shows your readers that you have an in-depth grasp of your subject and that you understand where your own research fits into and adds to an existing body of agreed knowledge. Another way of describing four main tasks of literature review are to demonstrates a familiarity with a body of knowledge and establishes the credibility of your work. To summarizes prior research and says how your project is linked to it. It integrates and summarizes what is known about a subject and also Royal Literacy Fund [6] demonstrates that you have learnt from others and that your research is a starting point for new ideas.

We conducted a rapid review to assess the effects Barbara [7] of quarantine alone or in combination with other measures of individuals who had contact with confirmed cases of COVID-19. Current evidence for COVID-19 is limited to modelling studies that make parameter assumptions based on the current fragmented knowledge. Findings consistently indicate that quarantine is important in reducing incidence and mortality during the COVID-19 pandemic. Early implementation of quarantine and combining quarantine with other public health measures is important to ensure effectiveness. In order to maintain the best possible balance of measures decision makers must constantly monitor the outbreak situation and the impact of the measures implemented. Testing in representative samples in different settings could help assess the true prevalence of Barbara [7] infection and would reduce uncertainty of modelling assumptions.

Table 1: 15 Randomly selected Articles to show focus on prevention and control of COVID-19 novel corona virus.

\begin{tabular}{|c|c|c|c|c|}
\hline S.NO & $\begin{array}{c}\text { Complete Reference of the Articles } \\
\text { selected for study }\end{array}$ & $\begin{array}{l}\text { Study Favors } \\
\text { Prevention and Control } \\
\text { of Covid-19 Novel } \\
\text { Corona Virus -Yes }\end{array}$ & $\begin{array}{l}\text { Study Ignores } \\
\text { Prevention and Control } \\
\text { of Covid-19 Novel } \\
\text { Corona Virus- No }\end{array}$ & $\begin{array}{l}\text { Percentage Agreed of } \\
\text { the Prevention and } \\
\text { Control of COVID-19 } \\
\text { Novel Corona Virus }\end{array}$ \\
\hline 1 & $\begin{array}{c}\text { Fan J, Liu X, Shao G, Qi J (2020) The epidemiology } \\
\text { of reverse transmission of COVID-19 in Gansu } \\
\text { Province, China. ELSEVIER Travel Medicine and } \\
\text { Infectious Disease }\end{array}$ & YES & ------- & $100 \%$ \\
\hline 2 & $\begin{array}{l}\text { Hasnain Jan, Shah Faisal, Ayyaz Khan Shahzar } \\
\text { Khan et al (2020) COVID-19: Review of } \\
\text { Epidemiology and Potential Treatments Against } \\
2019 \text { Novel Coronavirus. Discoveries Journals } \\
\text { 8(2): e108. }\end{array}$ & YES & ------ & $80 \%$ \\
\hline 3 & $\begin{array}{l}\text { Sevim Candan, Nuray Elibol, Auwal Abdullahi } \\
\text { (2020) Consideration of Prevention and } \\
\text { Management of Long-Term Consequences of Post- } \\
\text { Acute Respiratory Distress Syndrome in Patients } \\
\text { With COVID-19. Journal Physiotherapy Theory } \\
\text { and Practice 18: 1-6. }\end{array}$ & YES & ------ & $100 \%$ \\
\hline 4 & $\begin{array}{l}\text { Hussin A Rothan, Siddappa N Byrareddy } \\
\text { (2020) The Epidemiology and Pathogenesis } \\
\text { of Coronavirus Disease (COVID-19) Outbreak. } \\
\text { ELSEVIER Journal of Autoimmunity 109: 102433. }\end{array}$ & YES & ----- & $75 \%$ \\
\hline
\end{tabular}




\begin{tabular}{|c|c|c|c|c|}
\hline 5 & $\begin{array}{l}\text { Barbara S, Verena M, Andreea D2020) Quarantine } \\
\text { Alone or in Combination with Other Public } \\
\text { Health Measures to Control COVID-19: A Rapid } \\
\text { Review. Cochrane Database of Systematic } \\
\text { Reviews 4(4):CD013574. }\end{array}$ & YES & --.---. & $100 \%$ \\
\hline 6 & $\begin{array}{c}\text { Carlo C, Mariachiara Di Nuzzo, Nicole B (2020) } \\
\text { The Novel Zoonotic COVID-19 Pandemic: An } \\
\text { Expected Global Health Concern. Journal of } \\
\text { infection in Developing countries. } 2020 \text { Mar } \\
\text { 31;14(3): 254-264. }\end{array}$ & YES & --.---. & $100 \%$ \\
\hline 7 & $\begin{array}{c}\text { Shajeea Arshad Ali, Mariam Baloch, Naseem } \\
\text { Ahmed (2020) The Outbreak of Coronavirus } \\
\text { Disease } 2019 \text { (COVID-19)-An Emerging Global } \\
\text { Health Threat. } 2020 \text { Apr;13(4):644-646. }\end{array}$ & YES & ------ & $100 \%$ \\
\hline 8 & $\begin{array}{l}\text { Zhangkai J Cheng, Jing Shan (2020) } 2019 \text { Novel } \\
\text { Coronavirus: Where We Are and What We Know. } \\
\text { SPINGER Link Infection. } 2020 \text { Apr;48(2): 155- } \\
163 .\end{array}$ & YES & ------ & $70 \%$ \\
\hline 9 & $\begin{array}{c}\text { Yongshi Y, Fujun P, Runsheng W (2020) The } \\
\text { Deadly Coronaviruses: The } 2003 \text { SARS Pandemic } \\
\text { and the } 2020 \text { Novel Coronavirus Epidemic in } \\
\text { China. ELSEVIER Journal of Autoimmunity 109: } \\
102434 \text {. }\end{array}$ & YES & ------ & $100 \%$ \\
\hline 10 & $\begin{array}{c}\text { Shan-Lu Liu (2020) New Virus in China Requires } \\
\text { International Control Effort. NATURE Research } \\
\text { Journal 577(7791): } 472 .\end{array}$ & YES & ------ & $100 \%$ \\
\hline 11 & $\begin{array}{l}\text { Yuefei Jin, Haiyan Yang, Wangquan Ji (2020) } \\
\text { Virology, Epidemiology, Pathogenesis, and } \\
\text { Control of COVID-19. MCPI VIRUSES 12(4): E372. }\end{array}$ & YES & ----- & $20 \%$ \\
\hline 12 & $\begin{array}{l}\text { Carlo B, Christian C, Francesco P (2020) } \\
\text { Recommendations for the Prevention, Mitigation } \\
\text { and Containment of the Emerging SARS- } \\
\text { CoV-2 (COVID-19) Pandemic in Hemodialysis } \\
\text { Centers. OXFORD Academic Nephrology Dialysis } \\
\text { Transplantation 35(5): 737-741. }\end{array}$ & YES & --.---. & $100 \%$ \\
\hline 13 & $\begin{array}{l}\text { Darwiche K, Ross B, Gesierich W }(2020) \\
\text { Recommendations for Performing Bronchoscopy } \\
\text { in Times of the COVID-19 Pandemic. Thieme } \\
\text { Pneumologie Germany 74(5): 260-262. }\end{array}$ & YES & --.---. & $100 \%$ \\
\hline 14 & $\begin{array}{l}\text { Matthias Z, Emeka N (2020) Approaches to the } \\
\text { Management of Patients in Oral and Maxillofacial } \\
\text { Surgery During COVID-19 Pandemic. ELSEVIER } \\
\text { Journal of Cranio-Maxillofacial Surgery 48(5): } \\
\text { 521-526. }\end{array}$ & YES & ------ & $100 \%$ \\
\hline 15 & $\begin{array}{l}\text { Paul M, Russell M 2020) Aerosol-generating } \\
\text { Otolaryngology Procedures and the Need for } \\
\text { Enhanced PPE During the COVID-19 Pandemic: A } \\
\text { Literature Review. BMC Journal of Otolaryngology } \\
\text { Head \& Neck Surgery 49(1): } 29 \text {. }\end{array}$ & YES & ------ & $70 \%$ \\
\hline
\end{tabular}

After about 10 years in 2012 another similar Carlo [8] coronavirus triggered the Middle East Respiratory Syndrome MERS-CoV in Saudi Arabia. Both caused severe pneumonia killing 774 and 858 people with 8700 cases of confirmed infection for the former and 2494 for the latter causing significant economic losses. SARS-CoV-2 would seem to have come from a bat, but the intermediate reservoir continues to be unknown. Nonetheless as for SARS-CoV and MERS CoV the Spillover effect linked to animal human promiscuity human activities including deforestation illegal bush trafficking and bushmeat cannot be excluded. Recently however evidence of inter human only transmission of SARS-CoV-2 has been accumulated and thus the outbreak seems to be spreading by human-to-human transmission Carlo [8] throughout a large part of the world (Table 1).

Oral and maxillofacial surgery Matthias [9] is correlated with a high risk of SARS-CoV-2 transmission. During the peak of the pandemic no elective surgery should be performed. Even urgent procedures might be postponed if there is a view to recovery of a COVID-19 patient within a few days. Emergency procedures do not allow any delay. Specialties with overlap in therapies should have well defined arrangements among each other concerning the treatment spectra to avoid redundancy and loss of resources. Inpatient and outpatient units must be organized in such a way that the risk of cross-infection among patients is reduced to a minimum. Especially testing of patients for SARS-CoV-2 is important to detect the infected patients at an early stage. When surgery is performed on COVID-19 patients' adequate personal protective equipment is crucial. There must be negative pressure in the operating room and aerosol formation must be reduced to a minimum. To address the COVID-19 challenge adequately significant changes in the infrastructure of Matthias [9] outpatient units' inpatient units and operating rooms are needed. Measure and statistical Analysis: (IBM (2006) IBM SPSS Software) (Figure 5); (Table 2). 
Table 2: 15 Randomly selected articles to show focus on prevention and control of COVID-19 novel corona virus.
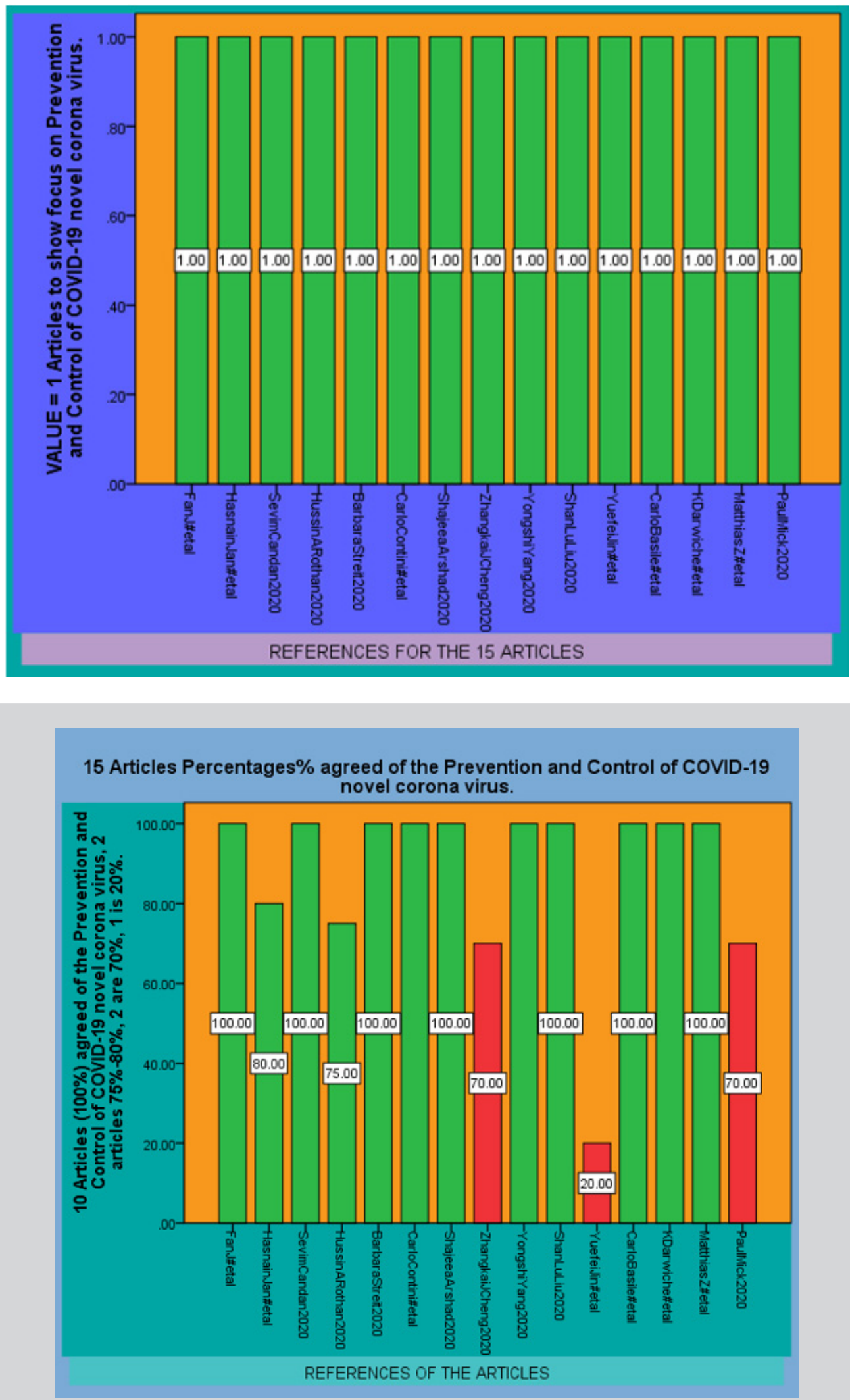

Figure 5: 15 Articles Percentages\% agreed of the Prevention and Control of COVID-19 novel corona virus.

\section{RESULTS}

Author of this articles has selected randomly 15 Articles from PUBMED and other sources for review and critical analysis about the Articles to focus on Prevention and Control of COVID-19 novel corona virus. First part of the table and SPSS1 Diagrammatic presentation shows that all 15 articles focus on implementation of policies and methods for Prevention and Control of COVID-19 novel corona virus. SPSS2 Diagrams shows the Percentages\% agreed of the Prevention and Control of COVID-19 novel corona virus where 10 Articles fully $100 \%$ qualified but 5 articles are below $81 \%$ which is low in percentage. 
Otolaryngology groups Paul [10] are recommending a higher level of personal protective equipment for aerosol-generating procedures than public health agencies. The objective of the review was to provide evidence that a.) demonstrates which otolaryngology procedures are aerosol-generating and that $\mathrm{b}$.) clarifies whether the higher level of PPE advocated by otolaryngology groups is justified. Experimental evidence has shown that electrocautery advanced energy devices open suctioning and drilling can create aerosolized biological particles. The viral load of COVID-19 is highest in the upper aerodigestive tract increasing the likelihood that aerosols generated during procedures of the upper aerodigestive tract of infected patients would carry viral material. Cough and normal breathing create aerosols which may increase the risk of transmission during outpatient procedures. Powered air purifying respirators if used properly provide Paul [10] a greater level of filtration than N95 masks and thus may reduce the risk of transmission.

Controlling the spread of emerging Shan-Lu [11] and reemerging viruses calls for international efforts. China's research collaborations and data sharing must continue including with the United States despite other problems with their relations. The authorities have been understandably cautious after the early misidentification of the SARS pathogen in 2003. However, the results of animal testing from a seafood market in Wuhan where the virus was initially isolated must be released as soon as possible. The virology community also feels that human-to-human transmission should not be ruled out without compelling evidence. This information is particularly crucial because tens of millions of people will be travelling and consuming potentially contaminated animal meat to celebrate the Chinese New Year Shan-Lu [11] on 25 January. The public needs clear instructions and guidance.

\section{DISCUSSION}

A Canadian Society of Otolaryngology Sommer [12] Head and Neck Surgery CSO-HNS task force was convened with multispecialty involvement from otolaryngology head and neck surgery general surgery, critical care and anesthesiology to develop a set of recommendations for the performance of tracheotomies during the COVID-19 pandemic. The tracheotomy procedure is highly aerosol generating and directly exposes the entire surgical team to the viral aerosol plume and secretions thereby increasing the risk of transmission to healthcare providers. As such we believe extended endotracheal intubation should be the standard of care for the entire duration of ventilation in the vast majority of patients. Preoperative COVID-19 testing is highly recommended for any nonemergent procedure. Recommendations for appropriate PPE and environment are made for COVID-19 positive Sommer [12] negative and unknown patients requiring consideration of tracheotomy.

Personal protective equipment PPE can Jos [13] reduce the risk by covering exposed body parts. It is unclear which type of PPE protects best what is the best way to put PPE on i.e. donning or to remove PPE i.e. doffing, and how to train HCWs to use PPE as instructed. We included all controlled studies that evaluated the effect of full body PPE used by HCW exposed to highly infectious diseases on the risk of infection contamination or noncompliance with protocols. We found low to very low certainty evidence that covering more parts of the body leads to better protection but usually comes at the cost of more difficult donning or doffing and less user comfort and may therefore even lead to more contamination. More breathable types of PPE may lead to similar contamination but may have greater user satisfaction. Modifications to PPE design such Jos [13] as tabs to grab may decrease the risk of contamination.

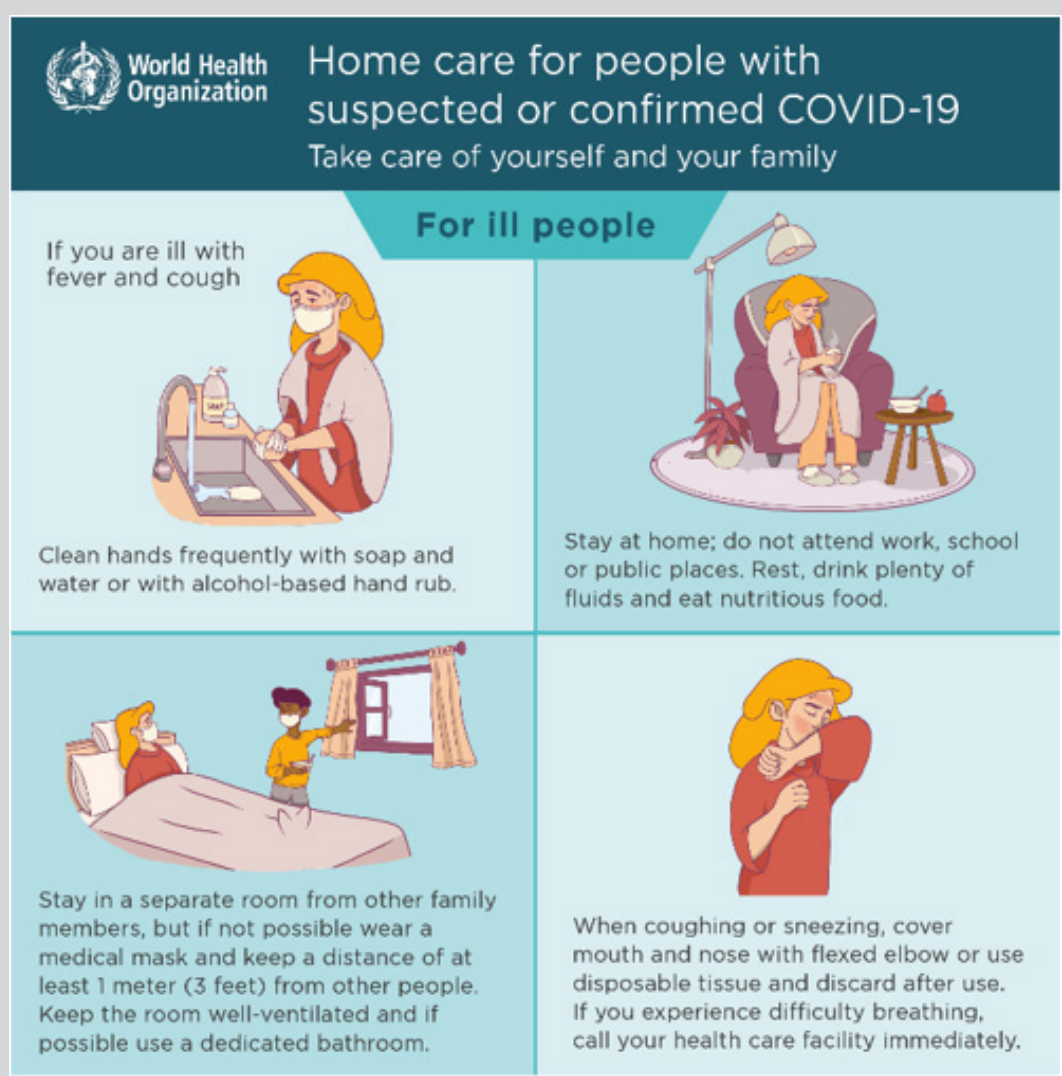

Figure 6: World Health Organization, 2020. 
The outbreak of Coronavirus Disease 2019 causing Shajeea [14] novel coronavirus infected pneumonia (NCIP) has affected the lives of 71,429 people globally. Originating in China the disease has a rapid progression to other countries. Research suggests remarkable genomic resemblance of 2019-nCoV with Severe Acute Respiratory Syndrome SARS which has a history of a pandemic in
2002. With evidence of nosocomial spread a number of diligent measures are being employed to constrain its propagation. Hence the Public Health Emergency of International Concern PHEIC has been established by the World Health Organization (WHO) with strategic objectives for public health Shajeea [14] to curtail its impact on global health and economy (Figure 6,7).

\section{(9) I'm pregnant. against COVID-19?}

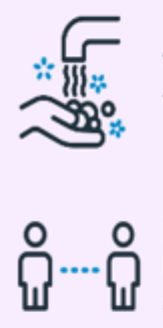

Wash your hands frequently

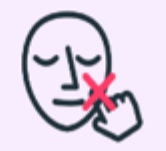

Avoid touching your eyes, nose and mouth

Cough or sneeze into your bent elbow or a tissue

If you have fever, cough or difficulty breathing, seek care early. Call beforehand, and follow medical advice.

Figure 7: World Health Organization, 2020.

Based on the large number of infected people Hussin [15] that were exposed to the wet animal market in Wuhan City China it is suggested that this is likely the zoonotic origin of COVID-19. Person-to-person transmission of COVID-19 infection led to the isolation of patients that were subsequently administered a variety of treatments. Extensive measures to reduce person-to-person transmission of COVID-19 have been implemented to control the current outbreak. Special attention and efforts to protect or reduce transmission should be applied in susceptible populations including children health care providers and elderly people. In this review, we highlight the symptoms epidemiology transmission pathogenesis phylogenetic analysis and future directions to control the spread of this fatal disease Hussin [15].

Governments are under Zhangkai [16] increased pressure to stop the outbreak spiraling into a global health emergency. At this stage preparedness transparency and sharing of information are crucial to risk assessments and beginning outbreak control activities. This information should include reports from outbreak sites and from laboratories supporting the investigation. This paper aggregates and consolidates the virology epidemiology clinical management strategies from both English and Chinese literature official news channels and other official government documents. In addition, by fitting the number of infections with a single term exponential model we report that the infection is spreading at an Zhangkai [16] exponential rate with a doubling period of 1.8 days.

Bats snakes and pangolins have been cited Yongshi [17] as potential carriers based on the sequence homology of CoV isolated from these animals and the viral nucleic acids of the virus isolated from SARS-CoV-2 infected patients. Extreme quarantine measures including sealing off large cities closing borders and confining people to their homes were instituted in January 2020 to prevent spread of the virus but by that time much of the damage had been done as human-human transmission became evident. While these quarantine measures are necessary and have prevented a historical disaster along the lines of the Spanish flu earlier recognition and earlier implementation of quarantine measures may have been even more effective. However, finding an effective antiviral and developing a vaccine are still significant challenges. The costs of the epidemic are not limited to medical aspects as the virus has led to Yongshi [17] significant sociological psychological and economic effects globally (Figure 8).

Uraemic patients on dialysis Carlo [18] combine an intrinsic fragility and a very frequent burden of comorbidities with a specific setting in which many patients are repeatedly treated in the same area hemodialysis centers. Moreover, if infected the intensity of dialysis requiring specialized resources and staff is further complicated by requirements for isolation control and prevention putting healthcare systems under exceptional additional strain. The aim of the present review of the European Dialysis EUDIAL Working Group of ERA-EDTA is to provide recommendations for the prevention mitigation and containment in hemodialysis centers of the emerging COVID-19 pandemic. The management of patients on dialysis affected by COVID-19 must be carried out according to strict protocols to minimize the risk for other patients and personnel taking care of these patients. Measures Carlo [18] of prevention protection screening isolation and distribution have been shown to be efficient in similar settings. 


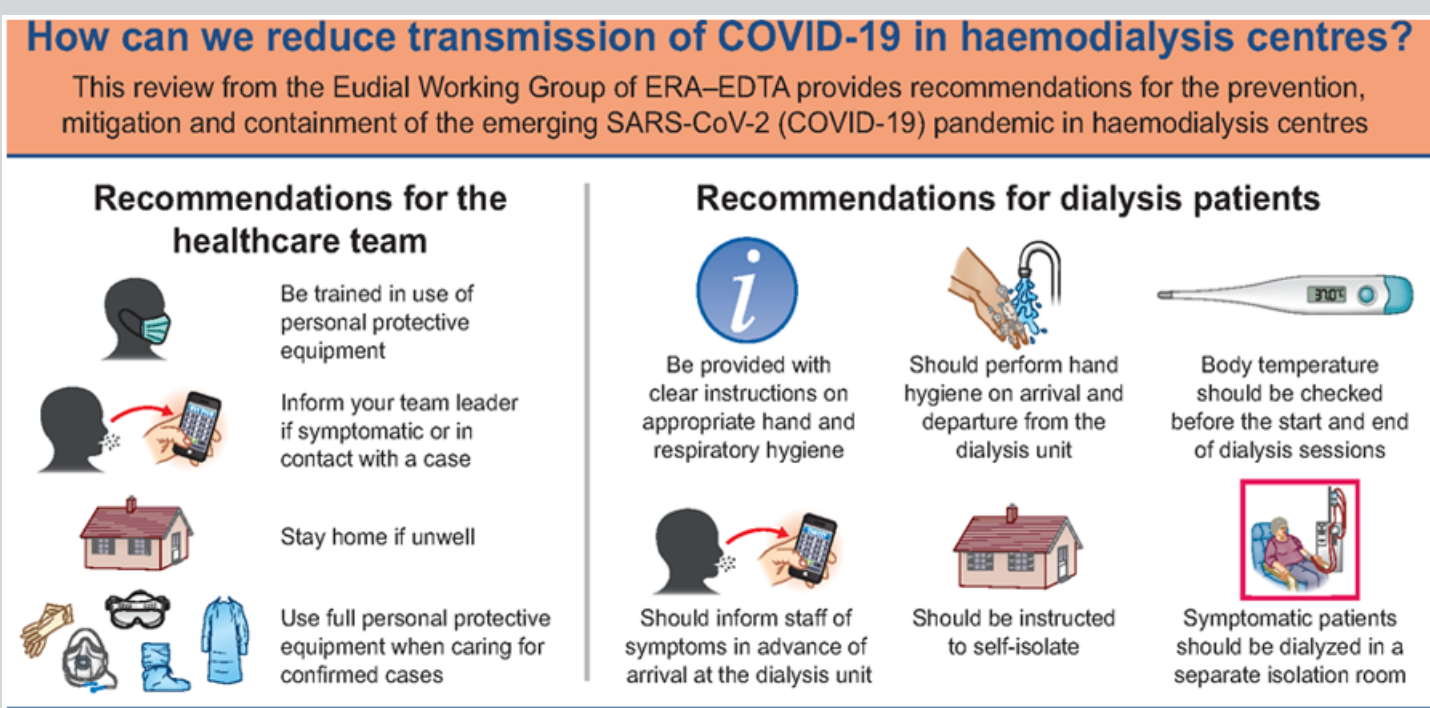

Figure 8: Carlo [18].

COVID-19 caused Darwiche [19] by coronavirus SARS-CoV-2 is a new and ongoing infectious disease affecting healthcare systems worldwide. Healthcare worker are at high risk for COIVD-19 and many have been infected or even died in countries severely affected by COVID-19 like China or Italy. Bronchoscopy causes cough and aerosol production and has to be considered a significant risk for the staff to get infected. Particular recommendations should guide to prevent spreading COVID-19 and to protect healthcare worker when performing a bronchoscopy Darwiche [19].

\section{CONCLUSION}

Current Pandemic of COVID-19 has taught us that we in the twenty first century is not ready to provide health care to vulnerable community such as elders, children and sick people with chronic illness. Such vulnerable people with bad health and low socioeconomic status are more prone to get effected by COVID-19 novel corona virus. More serious work needed to be done by Global health agencies and world organizations such as WHO, CDC, UN, UNESCO, UNHCR others. Governments and health departments has to make useful health policies to implement in deadlines with serious accountability to fight against any Epidemic or Pandemic [20].

\section{REFERENCES}

1. World Health Organization (2020) Coronavirus disease (COVID-19) advice for the public.

2. Fan J, Liu X, Shao G, Qi J (2020) The epidemiology of reverse transmission of COVID-19 in Gansu Province, China. ELSEVIER Travel Medicine and Infectious Disease 101741.

3. Hasnain J, Shah F, Ayyaz K, Shahzar K (2020) COVID-19: review of epidemiology and potential treatments against 2019 novel coronavirus. Discoveries Journals 8 (2): e108.

4. Sevim C, Nuray E, Auwal A (2020) Consideration of prevention and management of long-term consequences of post-acute respiratory distress syndrome in patients with COVID-19. Journal Physiotherapy Theory and Practice. 1-6.

5. Yuefei J, Haiyan Y, Wangquan Ji (2020) Virology, epidemiology, pathogenesis and control of COVID-19. MCPI VIRUSES. 12(4): E372.

6. Royal Literacy Fund (2020) What is a literature review?

7. Barbara S, Verena M, Andreea D (2020) Quarantine alone or in combination with other public health measures to control COVID-19: A rapid review. Cochrane Database of Systematic Reviews 4(4): CD013574.
8. Carlo C, Mariachiara Di N, Nicole B (2020) The novel zoonotic COVID-19 pandemic: An expected global health concern. Journal of infection in Developing countries 14(3): 254-264.

9. Matthias Z, Emeka N (2020) Approaches to the management of patients in oral and maxillofacial surgery during COVID-19 pandemic. ELSEVIER Journal of Cranio-Maxillofacial Surgery 48(5): 521-526.

10. Paul M, Russell M (2020) Aerosol-generating otolaryngology procedures and the need for enhanced PPE during the COVID-19 pandemic: A literature review. BMC Journal of Otolaryngology Head \& Neck Surgery 49(1): 29.

11. Shan-Lu Liu (2020) New virus in China requires international control effort. NATURE Research Journal 577(7791): 472.

12. Sommer DD, Engels P T, Weitzel EK (2020) Recommendations from the CSO-HNS taskforce on performance of tracheotomy during the COVID-19 pandemic. BMC Journal of Otolaryngology - Head \& Neck Surgery 49(1): 23.

13. Jos HV, Blair R, Sharea I (2020) Personal protective equipment for preventing highly infectious diseases due to exposure to contaminated body fluids in healthcare staff. Cochrane Database of Systematic Reviews 4(4): CD011621.

14. Shajeea AA, Mariam B, Naseem A (2020) The outbreak of coronavirus disease 2019 (COVID-19)-an emerging global health threat. Journal of Infection and Public Health 13(4): 644-646.

15. Hussin AR, Siddappa NB (2020) The epidemiology and pathogenesis of coronavirus disease (covid-19) outbreak. ELSEVIER Journal of Autoimmunity 109: 102433.

16. Zhangkai JC, Jing S (2020) 2019 Novel coronavirus: where we are and what we know. SPINGER Link Infection 48(2): 155-163.

17. Yongshi Y, Fujun P, Runsheng W (2020) The deadly coronaviruses: The 2003 SARS pandemic and the 2020 novel coronavirus epidemic in China. ELSEVIER Journal of Autoimmunity 109: 102434.

18. Carlo B, Christian C, Francesco P (2020) Recommendations for the prevention, mitigation and containment of the emerging SARS-CoV-2 (COVID-19) pandemic in hemodialysis centers. OXFORD Academic Nephrology Dialysis Transplantation 35(5): 737-741.

19. Darwiche K, Ross B, Gesierich W (2020) Recommendations for performing bronchoscopy in times of the COVID-19 pandemic. Thieme Pneumologie Germany 74(5): 260-262.

20. IBM (2006) IBM SPSS software. 